\title{
Changes in the germination process and growth of pea in effect of laser seed irradiation
}

\author{
Anna Podleśna ${ }^{*}$, Bożena Gładyszewska², Janusz Podleśny ${ }^{1}$, and Wojciech Zgrajka \\ ${ }^{1}$ Institute of Soil Science and Plant Cultivation - State Research Institute, Czartoryskich 8, 24-100 Puławy, Poland \\ ${ }^{2}$ Department of Physics, University of Life Sciences, Akademicka 13, 20-950 Lublin, Poland \\ ${ }^{3}$ Institute of Rural Health, Jaczewskiego 2, 20-090 Lublin, Poland
}

Received February 23, 2015; accepted October 12, 2015

A b s t r a c t. The aim of this study was to determine the effect of pre-sowing helium-neon (He-Ne) laser irradiation of pea seeds on changes in seed biochemical processes, germination rate, seedling emergence, growth rate, and yield. The first experimental factor was exposure to laser radiation: D0 - no irradiation, D3 three exposures, D5 - five exposures, and the harvest dates were the second factor. Pre-sowing treatment of pea seeds with $\mathrm{He}-\mathrm{Ne}$ laser light increased the concentrations of amylolytic enzymes and the content of indole-3-acetic acid (IAA) in pea seeds and seedlings. The exposure of seeds to He-Ne laser light improved the germination rate and uniformity and modified growth stages, which caused acceleration of flowering and ripening of pea plants. Laser light stimulation improved the morphological characteristics of plants by increasing plant height and leaf surface area. Irradiation improved the yield of vegetative and reproductive organs of pea, although the effects varied at the different growth stages. The increase in the seed yield resulted from a higher number of pods and seeds per plant, whereas no significant changes were observed in the number of seeds per pod. Both radiation doses exerted similarly stimulating effects on pea growth, development, and yield.

K e y w o r d s: He-Ne laser, IAA, amylolytic enzymes, physiological parameters of growth, pea yield

\section{INTRODUCTION}

Legumes play an important role in sustainable agriculture of European countries. One of the major legume plants, grown in the warm temperate transitional climate zone, is pea cultivated for human and animal consumption. In spite of its beneficial effect on the environment, plant cultivation, and a protein source in fodder production, pea land is very low in European farming systems (Voisin et al., 2014). The small acreage of pea in Poland is caused mainly by low and fluctuating yields (Szwejkowska, 2006).

*Corresponding author e-mail: ap@iung.pulawy.pl
On the other hand, in agricultural practice, there is a growing demand for high quality and environmentally safe products. This prompts producers to restrict the use of chemical agents containing some active substances that can modify the chemical composition of seeds and contaminate soil. Therefore, there is a need for finding possibilities of increasing pea yields and ensuring its quality. This is possible to achieve by agricultural and physical treatments as in the case of other legumes (Podleśny, 2002; Podleśny and Podleśna, 2004) and other plant species (Hernandez et al., 2009; Osman et al., 2009; Tobgy et al., 2009). However, according to some authors, the best method to combine these goals is the use of physical treatments (Delibatowa and Ivanova, 2006; Flórez et al., 2007; Hernandez et al., 2010; Jun et al., 2007; Podleśny et al., 2004; Rochalska and Orzeszko-Rywka, 2008). In some researches opinion, presowing physical treatments of seeds are environmentally safe because they only modify biochemical and physiological processes in seeds, which, in consequence, accelerate seedling emergence and improve plant development (Chen et al., 2005a; Podleśny et al., 2012; Rubinov, 2003). Physical treatments, such as laser irradiation, do not replace chemical methods, but they can supplement them (Ouf and Abdel-Hardy, 1999; Vasilevski, 2003). Laser beams are monochromatic, coherent, and parallel; hence, they seem to be particularly suited for stimulating seeds (Ćwintal et al., 2010; Hernandez et al., 2006; Muszyński and Gładyszewska, 2008; Podleśny and Podleśna, 2004; Makarska et al., 2004). However, there are no scientific studies on the influence of laser beams on biochemical changes in pea seeds and seedlings in the process of germination. Seed germination is an important process affecting

(C) 2015 Institute of Agrophysics, Polish Academy of Sciences 
crop production, and is influenced by a range of factors, including enzymes and hormones. Plant hormones eg auxin (IAA), abscisic acid (ABA), cytokinins and others are biochemical substances that control many physiological and biochemical processes in the plant (Miransari and Smith, 2014). The activity of the amylase enzyme also determines the germination ability and viability of seeds (Nandi et al., 1995). This is important because plants grown from seeds with high viability are characterized by higher growth potential, more resistance to environmental stressors, as well as lesser susceptibility to disease and requirement for chemical protection.

The objective of this study was to determine the effect of pre-sowing seed irradiation by laser light on biochemical and physiological factors affecting the germination rate, seedling emergence, growth rate, and yield in pea.

\section{MATERIAL AND METHODS}

The experiment was performed in a greenhouse of the Institute of Soil Science and Plant Cultivation - State Research Institute in Puławy, Poland. Ten pea seeds $c v$. Ramrod were sown per one Mitscherlich pot filled with a mixture of $5 \mathrm{~kg}$ of Hortisol and $2 \mathrm{~kg}$ of sand. The seed germination capacity amounted to $94 \%$, the thousand seed weight was $224 \mathrm{~g}$, and their moisture was about $14 \%$. Seedlings were thinned directly after emergence, and five plants were left per pot. The following nutrient doses were applied (in $\mathrm{g} \mathrm{pot}^{-1}$ ): $\mathrm{N}-0.1, \mathrm{P}-1.1$, and $\mathrm{K}-1.4$. Liquid fertilizers were diluted in water and applied to the emerged seedlings. Demineralized water was used for watering the plants, and soil moisture was kept at $60 \%$ field capacity throughout the growing season. The amount of water supplied to the pot was determined by the gravimetric method.

The first experimental factor was exposure to laser radiation: D0 - no irradiation, D3 - three exposures and D5 - five exposures. The second factor were harvest dates, corresponding to plant development stages - BBCH (German abbreviation: Biologische Bundesanstalt, Bundessortenamt und Chemische Industrie): T1 - seedling stage, plant height approx. 4-5 cm (BBCH 10), T2 - 5-6 leaf stage, beginning of bud formation, plant height approx. $16-18 \mathrm{~cm}$ (BBCH 15), T3 - flowering stage, plant height approx. 55-60 cm (BBCH 65), T4 - pod setting and beginning of seed filling, plant height approx. $65-75 \mathrm{~cm}(\mathrm{BBCH}$ $70)$, T5 - fully ripe stage, approx. $90-95 \%$ blackened pods, seed moisture approx. 18-22\% (BBCH 90). Three and five exposures were used in this experiment on the basis of literature and our preliminary studies.

Seeds were irradiated at the Department of Physics of the University of Life Sciences in Lublin using a device for pre-sowing laser treatment of seeds (Gładyszewska, 2011). A helium-neon laser emitting red light at a wavelength of $\lambda=660 \mathrm{~nm}$ was used. The single-dose exposure was $4 \times 10^{-3} \mathrm{~J} \mathrm{~cm}^{-2} \mathrm{~s}^{-1}$ and the time of exposition was $1 \mathrm{~s}$. The spot size of the laser was $20 \mathrm{~mm}$ and it was focused. Dry seeds of pea were stimulated with $\mathrm{He}-\mathrm{Ne}$ laser beams during their free falling.

The seeds used for determination of the activity of amylolytic enzymes were sown in Petri dishes and analyzed on eight dates: immediately after irradiation and 12, 24, 48, $72,96,120$, and $144 \mathrm{~h}$ after this treatment. Experimental seeds were compared with control seeds, which had not been exposed to laser radiation. Enzyme activity was determined based on the amount of glucose released from starch (I) by enzymes in the supernatant solution. The glucose content was determined by the modified Somogyi-Nelson method (1952), which is used in biochemical analyses to determine the content of reducing sugars. This method involves the reduction of an arsenomolybdate reagent with copper (I) ions formed in the solution by the reaction of copper (II) ions with reducing sugars. Colour intensity was determined colorimetrically at $\lambda=520 \mathrm{~nm}$. The content of reducing sugars was determined based on a model curve for glucose solutions.

Indole-3-acetic acid (IAA) content was determined by HPLC (High-Performance Liquid Chromatography) and the modified Hardin and Stutte method (1981). The analytical procedure was described in detail by Podleśny (2002).

The number of the emerged seedlings was determined at $24 \mathrm{~h}$ intervals after the emergence of the first plants. Plants were counted until no new seedlings emerged in the pots. The emergence rate index $\left(E_{d}\right)$ was calculated based on the following equation:

$$
E_{d}=\frac{N_{e}}{N_{s}} 100 \%,
$$

where: $N_{e}$ - number of emerged plants, $N_{s}$ - number of sown seeds.

Only normally germinating seeds and fully developed plants were counted.

To determine the rate of the dry weight increase, the plants were harvested on dates T1-T5, and the dry weight of aboveground parts and roots was determined. Roots were washed in dense metal sieves. Dry matter content was determined by oven drying at $105^{\circ} \mathrm{C}$ using the gravimetric method (Wood and Roper, 2000).

Leaf area and chlorophyll content in leaves were determined as SPAD values (Soil Plant Analysis Development) on dates T2-T4 using the AM 300 leaf area meter (BioScientific Ltd., UK) and the SPAD-502 chlorophyll meter (Minolta, Japan), respectively. The SPAD index was determined on the first, second, and third fully developed topmost leaf as an average of 30 measurements in each pot and expressed in absolute SPAD units. The presented SPAD values for each experimental object are a mean of 4 measurements (pots).

The weight of seeds per plant, the number of pods per plant, the number of seeds per pod, and the number of seeds per plant were determined during harvest at the fully ripe 
stage. Seed moisture content was calculated. Seed yield at the fully ripe stage was calculated for the $14 \%$ moisture content and expressed per experimental unit ie per pot.

Detailed observations of the growth and development of the pea plants were conducted throughout the experiment. Plant height was measured on dates T1-T5.

The activity of amylolytic enzymes and the IAA content of seeds and seedlings were determined in three series and four replications.

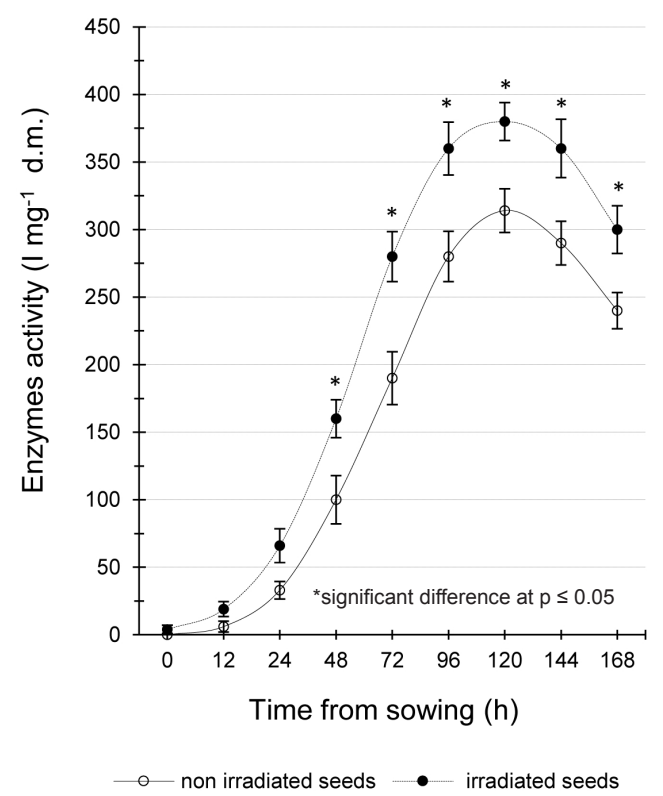

Fig. 1. Changes in the activity of amylolytic enzymes in seeds depending on irradiation and time from sowing.

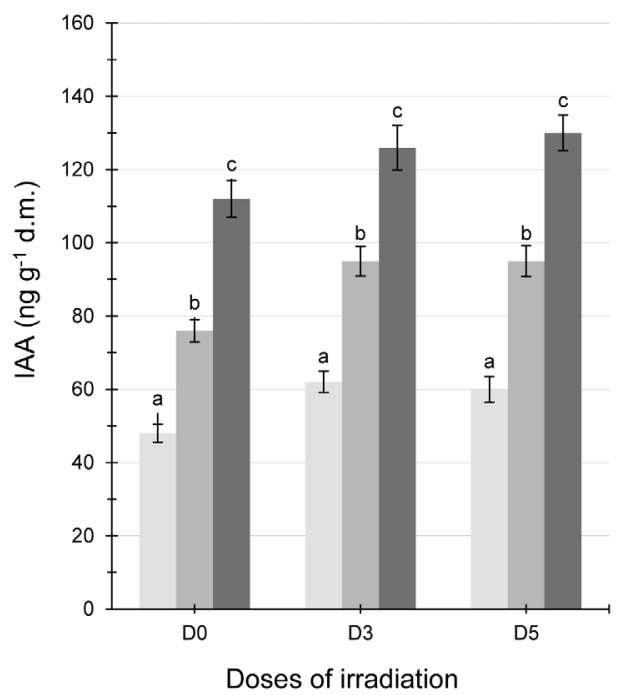

Fig. 2. Content of IAA in the seeds depending on the dose of laser irradiation. Values within a bar followed by different letters are significantly different at $\mathrm{p} \leq 0.05$
The results of the experiment conducted in Mitscherlich pots were expressed in terms of average values per 4 pots. The data obtained were processed statistically in the Statgraphics Plus 5 application at a significance level of $\mathrm{p} \leq 0.05$.

\section{RESULTS}

The biochemical analysis showed that laser light enhanced the activity of amylolytic enzymes during the whole time of research duration; however, its stimulating effect was the lowest at the early stages of germination before the seeds were fully imbibed (Fig. 1). The activity of amylolytic enzymes in pea seeds increased with time and peaked $120 \mathrm{~h}$ after seed sowing (380 $\mathrm{I} \mathrm{g}^{-1}$ d.m.), while after $168 \mathrm{~h}$ from sowing their activity decreased to $238 \mathrm{I} \mathrm{g}^{-1} \mathrm{~d}$.m. Three and five exposures to laser radiation caused a similar increase in the activity of these enzymes, and therefore the noted changes were expressed on a regression curve as average values for both radiation doses.

The IAA content of pea seeds increased with time and peaked 168 hours after sowing in seeds treated and not treated with laser light (Fig. 2). Three and five exposures to laser radiation produced a similar increase in the IAA content in the pea seeds. For both radiation doses, the average increase in IAA concentrations after 24, 96, and $168 \mathrm{~h}$ from sowing reached $27.1,25.0$, and $14.3 \%$, respectively, in comparison with control seeds.

The emergence rate of seedlings $\left(E_{d}\right)$ in the object with laser irradiation began to grow from the fifth day after sowing (DAS) and a dynamic increase in the emergence rate was observed up to 13 DAS (Fig. 3). In turn, the $E_{d}$ of seedlings from non-treated seeds had the same dynamics but it was 2 days delayed and had lower values in comparison with seedlings originating from the irradiated seeds. The highest values of $E_{d}$ for the irradiated and control seeds

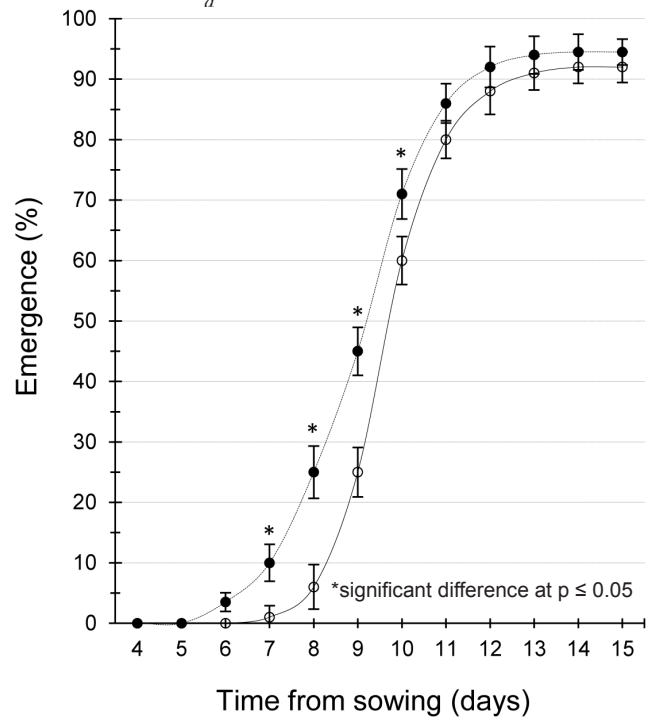

Fig. 3. Plant emergence dynamics - percent of emerging plants. Explanations as in Fig. 1 


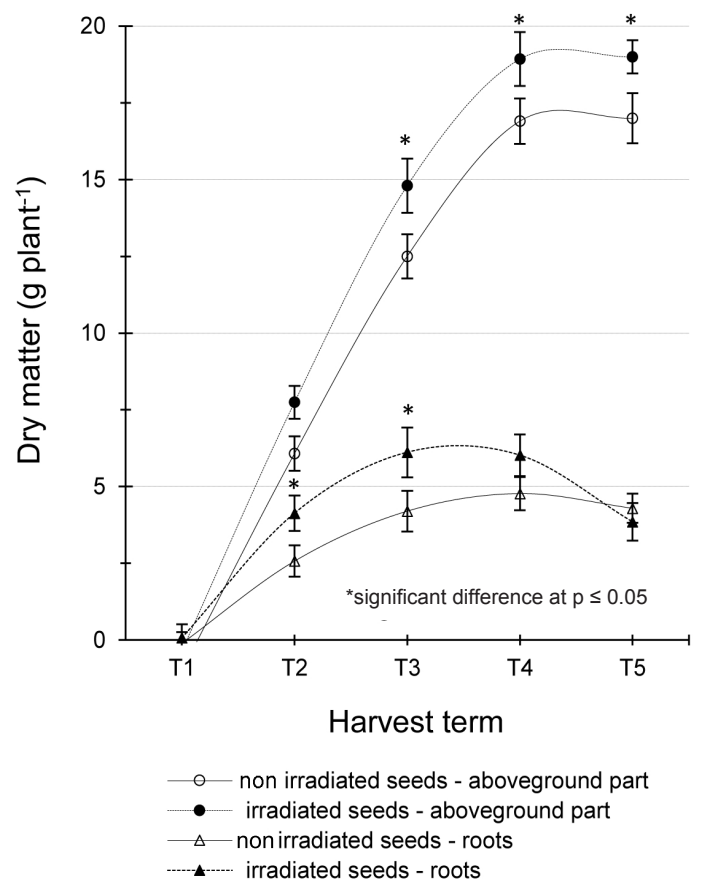

Fig. 4. Dynamics of the dry matter increase in the aboveground part and roots of pea plants grown from seeds irradiated and not irradiated with laser ligh.

were observed at $13(94.5 \%)$ and 15 DAS $(92.0 \%)$, respectively. No differences in $E_{d}$ and emergence uniformity were observed between plants grown from seeds that had been exposed to three- and five-time radiation.

Irradiation had an effect on the increase in dry matter of aboveground parts but this was more visible in the later periods of growth (Fig. 4). The highest increase in the dry weight of roots and the aboveground parts of pea was observed between T1 and T3-T4 harvest dates, ie from the 5-6 leaf stage to the flowering - pod-setting stage. Successive growth stages brought an increase in the dry weight of aboveground parts. Root dry matter had a growing tendency up to T3 in the case of irradiated seeds and to T4 in the control object. From this period, a decrease in roots mass was found. Root dry matter of plants grown from irradiated seeds decreased faster than the roots mass

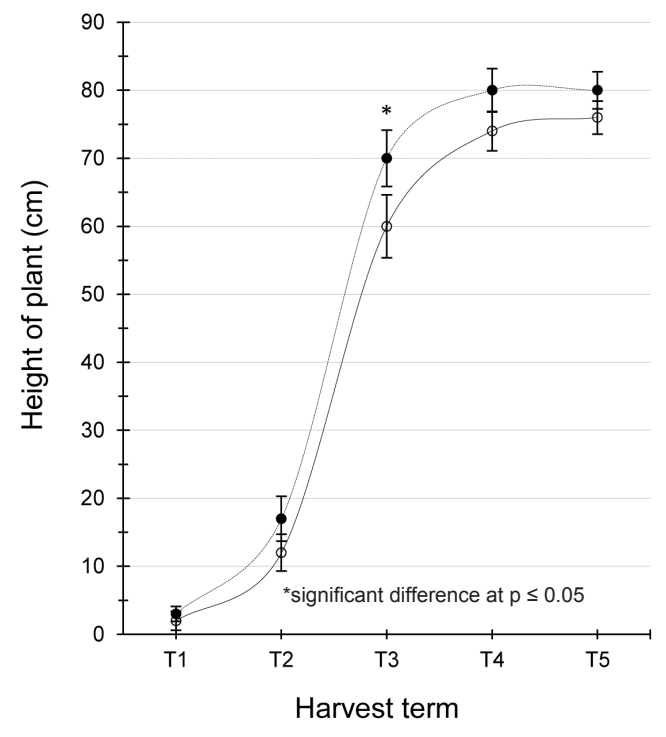

Fig. 5. Growth curve of pea plants grown from seeds treated and not treated with laser light.

of the control plants (D0). In consequence, roots of mature plants originating from seeds treated with laser beams had lower mass than those grown from non-irradiated seeds. Three and five exposures to laser radiation led to a similar increase in the dry weight of aboveground parts and roots; therefore, their average values are presented in Fig. 4.

Some differences in growth and development were observed between plants grown from irradiated and control seeds. Plants that developed from irradiated seeds were taller (Fig. 5) and they flowered and ripened around 3-4 days earlier than plants grown from control seeds. The differences in the height of the compared plant groups were maintained throughout the growing season, but they were significant at the flowering stage. Earlier ripening of plants grown from irradiated seeds was also manifested by lower water content in their seeds, in comparison with the seeds from the control treatment (Table 1).

Plants grown from irradiated seeds produced larger leaf area than plants grown from control seeds (Fig. 6). Significant differences were found in the period of bud

T a b l e 1. Yield of pea and yield components after seed pre-treatment with He-Ne laser

\begin{tabular}{lcccc}
\hline \multirow{2}{*}{ Description } & Yield of seeds & \multicolumn{2}{c}{ Number of seeds } & Number of pods \\
\cline { 3 - 3 } & $\left(\mathrm{g} \mathrm{pot}^{-1}\right)$ & plant $^{-1}$ & pod $^{-1}$ & $\begin{array}{c}\text { Moisture of seeds } \\
(\%)\end{array}$ \\
\hline
\end{tabular}

Doses of irradiation:

$3.6 \pm 0.16 \mathrm{a}$

$3.6 \pm 0.18 \mathrm{a}$

$24.9 \pm 0.28 \mathrm{c}$

$20.3 \pm 0.24 \mathrm{a}$

$22.2 \pm 0.36 b$
D0

D3

D5
$6.01 \pm 0.14 \mathrm{a}$

$6.68 \pm 0.08 \mathrm{~b}$

$6.72 \pm 0.04 \mathrm{~b}$
The same letters are not statistically different at $\mathrm{p} \leq 0.05, \mathrm{n}=3$. 


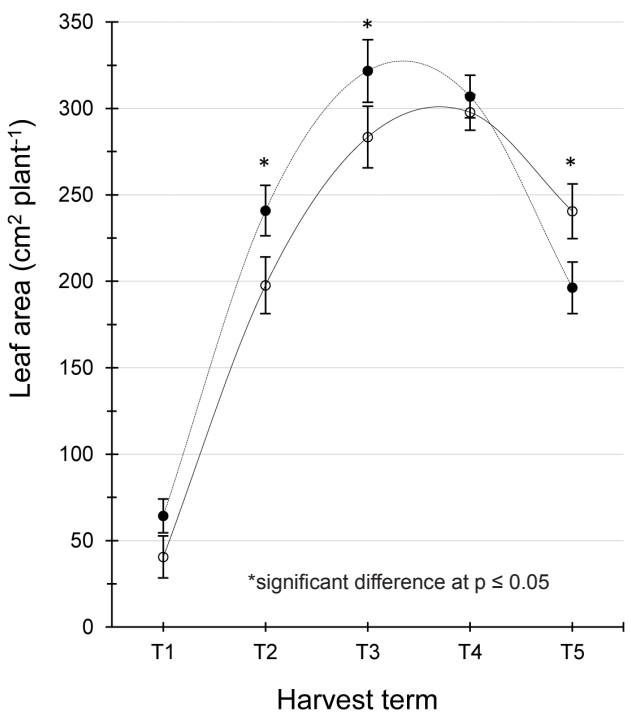

Fig. 6. Change in the leaf area of pea plants grown from seeds treated and not treated with laser light. Explanations as in Fig. 5.

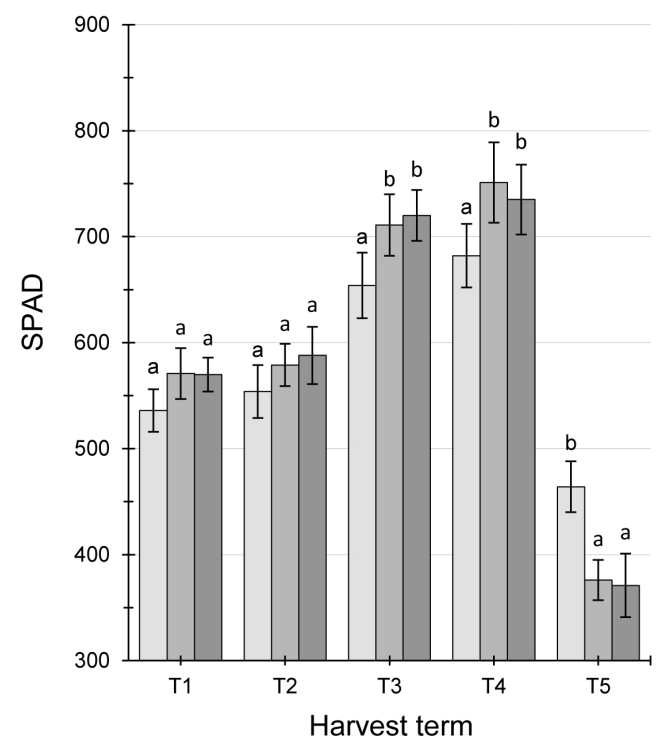

Fig. 7. Value of the soil plant analysis development (SPAD) index of pea plants grown from seeds treated and not treated by laser light. Values within a bar followed by different letters are significantly different at $\mathrm{p} \leq 0.05$.

formation (T2) and flowering (T3). The increase in leaf area resulted from an increase in the area of a single plant because the number of leaves per plant did not change in consequence of seed irradiation. There was a trend towards a higher number of leaves per plant grown from irradiated seeds, but the differences were statistically non-significant (data not shown).

The leaf area and the leaf chlorophyll content (SPAD index) were also affected by laser radiation. The highest SPAD index was found at pod setting (T4), lower during flowering (T3), and the lowest in the bud formation (T2) phase (Fig. 7). Seed irradiation significantly increased leaf chlorophyll content in the flowering and pod-setting stages.

The exposure of pea seeds to three and five radiation treatments increased the seed yield by 11.2 and $11.9 \%$, respectively. These increase in the yield resulted from a higher number of pods per plant and a higher number of seeds per plant (Table 1). Plants grown from control seeds produced an average of 5.6 pods, while plants grown from seeds exposed to three and five radiation treatments formed 6.2 and 6.4 pods, respectively. Seed irradiation had no significant influence on the number of seeds per pod but this treatment caused a significant decrease in seed moisture during the harvest.

\section{DISCUSSION}

Seed germination is one of the important processes in the plant life cycle since it determines the development and crop production. The germination process is a series of steps, which starts with imbibition, in effect of water uptake, followed by emergence of the radical from the seed coat where a number of physiological and metabolic processes are associated (Gujjaiah and Kumari, 2013). Before a seed can germinate, the availability of food stories in the seed (starch, protein, lipid, and nutrients) must be completed because these reserve substances are the metabolic energy and carbon skeleton for the synthesis of new protoplasm, structural components, and embryo development (Nandi et al., 1995; Miransari and Smith, 2014). Hydrolytic enzymes such as amylases play an essential role in the breakdown of reserve starch and proteins, which is necessary for emergence of the radical (Gujjaiah and Kumari, 2013). According to Nandi et al. (1995), the extent of amylase activity determines germination ability. However, the course of processes involved in the seed germination and metabolism of the compounds mentioned above can be affected by a number of environmental factors such as irradiance, temperature, salinity, drought, and type of ions present (Bohnert et al., 1995).

The results of our study indicate that the pre-sowing irradiation of seeds induced significant changes in the activity of amylolytic enzymes. Particularly high differences in enzyme activity between the irradiated and control seeds were observed during the later stages of germination $(120 \mathrm{~h}$ after sowing) when seeds were sufficiently imbibed with water. Jamil et al. (2013) also found a significant positive effect of pre-sowing laser treatment of wheat seeds on the $\alpha$-amylase activity but its maximum increase was observed about $48 \mathrm{~h}$ after sowing. According to Makarska et al. (2004), Hernandez et al. (2006), Jun Lin et al. (2007), and Ćwintal et al. (2010), the effects of laser radiation are particularly visible in germinating seeds and seedlings, which suggests that the underlying mechanisms of radiation should be investigated through biochemical and physiological analyses of seeds and young plants. We know at present 
that laser stimulation enables the seed cell to absorb and store radiant energy, which is then converted to chemical energy as a useable form in subsequent growth processes (Jamil et al., 2013). The above observation is substantiated by studies that confirmed the positive effects of laser radiation on enzyme activity at the early stages of germination (Chen et al., 2005b; Perveen et al., 2010; Rubinov, 2003).

According to Chen et al. (2005a) and Jamil et al. (2013), the He-Ne laser enhances enzyme activities and accelerates enzyme-mediated reactions ( $e g$ the rate of decomposition of a lower-entropy macromolecule) through the electromagnetic field and heat energy affecting molecules in the cell. It also enhances biological activity, finally leading to enhancement of the enthalpy, entropy, and initial energy of seeds during seed germination. Therefore, the laser treated plant group probably absorbed more energy from the surroundings than the control plants, and finally the metabolism of these plants was enhanced. These changes suggest that He-Ne laser pre-treatment can improve the inner energy of seeds, lead to enhancement of cotyledon enzymes, and speed up the metabolism of the cell, resulting from significantly increased emitted ultra-weak light commonly referred to as 'biophoton emission'. Devaraj et al. (1997) suppose that dividing cells emit ultra-weak far-UV light (photon) that is capable of inducing cell division in non-dividing cells. It is generally considered that ultra-weak photon emission originates from oxidative metabolic reactions in plant cells (Cifra and Pospišil, 2014). The dissipation of the absorbed laser energy took place in the embryo, causing a break in seed dormancy through an increase in the swelling rate and activity of enzymes that control the biochemical processes of germination (Ouf and Adbel-Hady, 1999). However, processes leading to seed germination are controlled by specific genes; therefore, it can be supposed that laser light exerts an effect at a molecular level. Graeber et al. (2012) found genes that control dormancy, including maturating genes, hormonal and epigenetic regulating genes, and genes that control release from dormancy.

Miransari and Smith (2014) underline the significance of plant hormones in the germination process. Among other roles of hormones, their effect on seed germination may be one of the most important functions in plant growth. In this process, an important role is played by auxin - IAA (Tillberg, 1977). This auxin is not a necessary hormone for seed germination; however, it is present in the seed radicle tip during and after seed germination (Miransari and Smith, 2014). The results obtained in our experiment showed a significant increase in the IAA concentration in the seeds exposed to laser radiation in comparison with the control seeds. Moreover, its concentration had a growing tendency along the time from sowing, but the seedlings grown from the laser treated seeds were richer in IAA than the control ones. We showed that laser light had a beneficial effect on the initial growth of young pea plants. Miransari and Smith
(2014) also found that IAA is necessary for the growth of young seedlings. According to these authors, the growth and development of different plant parts, including the embryo, leaf, and root can be controlled by auxin transport and this kind of regulation is affected by the transcriptional factors. Earlier, Tillberg (1977) proved that auxins are active in cell wall growth by influencing membrane properties, enzyme synthesis, and enzyme activation. Their role in the initiation, differentiation, and initial growth of tissues is known. It seems then possible that IAA present in germinating seeds is important at least for cell division and cell growth occurring in the growing embryo and its concentration can increase after treatment of seeds with laser light.

The pre-sowing laser treatment contributed to the uniformity and rate of seedling emergence. Most research on the effect of laser radiation on germination capacity and seedling emergence was conducted on cereal plants (Chen et al., 2010; Dinoev et al., 2006; Makarska et al., 2004; Rybiński and Garczyński, 2004), whereas pea was rarely investigated (Podleśny and Podleśna, 2004). A majority of these studies were focused on two plant growth stages ie emergence and yielding. The impact of radiation on changes in plant growth and development has been rarely analyzed (Delibatova and Ivanova, 2006; Jun Lin et al., 2007). Our study investigated the growth and development of pea plants by determining the increase in plant height, dry weight of roots and aboveground parts, and changes in selected yield-forming traits. The leaf area and the SPAD index, which reflects the leaf chlorophyll content, were determined as indicators of photosynthetic activity. Our findings showed that laser radiation had a positive effect on the investigated yield-forming factors.

The larger leaf area during vegetative growth of plants that developed from the irradiated seeds resulted probably from a faster growth rate in comparison with the control plants. Then the decrease in leaf area at the last stages of growth could be attributed to earlier plant maturation. Similar changes were reported in SPAD readings, although greater chlorophyll content in plants grown from the laser treated seeds persisted until the pod-setting and seed filling stages. Generally, there is a scarcity of studies on the effect of laser radiation on the physiological indicators of plant productivity. However, Dinoev et al. (2006) and Rybiński and Garczyński (2004) observed that barley, wheat, and maize plants grown from irradiated seeds were characterized by a larger leaf area in comparison with plants grown from untreated seeds. Next, in the research of Hernandez et al. (2009), laser stimulation of seeds caused an increase in the chlorophyll content in maize leaves. According to Ouf and Adbel-Hady (1999), laser irradiation might interact with a gene responsible for chlorophyll synthesis because the pathway of chlorophyll biosynthesis is catalysed by photo-enzyme protochlorophyllide oxidoreductase (POR), which is controlled by a definite gene. 
Seed irradiation increased the yield of vegetative and reproductive organs of pea plants. The dry weight of vegetative organs was increasing rapidly until the pod-setting stage, after which it considerably decreased. The drop in the weight of leaves and stems can be partly attributed to dry weight loss in the respiration process (Kinugasa et al., 2005). The increase in seed weight was higher than the increase in total biomass weight during pod setting, which suggests that the decrease in the weight of vegetative organs resulted also from the transfer of organic matter from leaves and stems to the developing pods. In turn, the dynamics of the roots dry weight increase in pea plants originating from the irradiated seeds was different from that in the control plants. From the seedling (T1) to the pod-setting (T4) stage, it had a strongly increasing tendency, and then it decreased below the weight value of the control plants. Therefore, we can suppose that laser radiation had a positive effect on root system development at these important phases of growth in pea as a legume plant. The main aspect of this growth period is development of nodules in which a key process termed nitrogen fixation takes place. It is possible that laser beams influenced the increase in root length (Jamil et al., 2013) and the number and weight of pea nodules as in the case of soybean (Ouf and Abdel-Hady, 1999). The drop in the dry weight of roots can be attributed to the faster end of root function and their withering as well as the loss of nodules on old roots and decomposition of aging roots.

An analysis of yield components revealed that the increase in the seed yield of pea from the laser treated group, resulted from the higher number of pods per plant. In legume plants, this trait changes under the influence of different yield-forming factors, although it is considered as a main component of pea yield structure (Szwejkowska, 2006). Therefore, the increase in the number of pods per plant in effect of laser treatment is beneficial from the agricultural point of view. It is probably connected with the faster development of pea plants grown from irradiated seeds because a greater increase in their aboveground and roots dry matter was observed from the beginning of growth. These plants had also greater leaf area, which in addition was richer in chlorophyll until the pod-setting phase (T4). According to Dinoev et al. (2006) as well as Rybiński and Garczyński (2004), laser irradiation intensifies the processes of photosynthesis and transpiration in plants. Therefore, it is probable that the laser treated pea had greater photosynthetic activity and supplied more assimilates to nodules, which could have influenced other processes in the plants because symbiotic nitrogen fixation directly depends on the current assimilate supply. In the research of Voisin et al. (2003), N fixation was linearly increasing with the amount of $\mathrm{C}$ allocated to nodulated roots. Therefore, it can be supposed that the plants grown from irradiated seeds developed more nodules (Ouf and Abdel-Hady, 1999) and fixed more nitrogen, which could be transferred to the new pods. The next element of yield structure - the number of seeds per pod is the least variable trait, and laser radiation had no significant effect on its value as in the case of white lupine (Podleśny, 2002). Significantly lower moisture levels in these seeds were also found, in comparison with the control, which could be a result of accelerated growth and maturation of plants as well as earlier finishing of the function of the root system. The beneficial impact of laser radiation has also been found in the case of the other crop species (Hernandez, 2010; Osman et al., 2009; Tobgy et al., 2009).

\section{CONCLUSIONS}

1. Pre-sowing irradiation of pea seeds with heliumneon laser light significantly increased the concentration of amylolytic enzymes and IAA hormone in the pea seeds and seedlings.

2. The exposure of pea seeds to laser radiation significantly accelerated the seedling emergence, improved emergence uniformity, and modified the plant growth stages.

3. Laser stimulation of pea seeds affected the morphological traits of plants by a significant increase in plant height and leaf surface area as well as by improvement of vegetative organs and seed yield of pea plants.

4. The radiation doses ( 3 and 5 exposures) exerted the same stimulating effects on pea growth, development, and yield.

\section{REFERENCES}

Bohnert H.J., Nelson D.E., and Jensen R.G., 1995. Adaptations to environmental stresses. Plant Cell, 9, 1099-1111.

Chen Y.P., Jia J.F., and Yue M., 2010. Effect of $\mathrm{CO}_{2}$ laser radiation on physiological tolerance of wheat seedlings expose to chilling stress. Photochem. Photobiol., 86, 600-605.

Chen Y.P., Liu Y.J., Wang X.L., Ren Z.Y., and Yue M., 2005a. Effect of microwave and He-Ne laser on enzyme activity and biophoton emission of Isatis indigotica fort. J. Integr. Plant Biol., 47, 849-855.

Chen Y.P., Yue M., and Wang X.J., 2005b. Influence of He-Ne laser irradiation on seeds thermodynamic parameters and seedlings growth of Isatis indigotica. Plant. Sci., 168, 601-606.

Cifra M. and Pospišil P., 2014. Ultra-weak photon emission from biological samples: Definition, mechanism, properties, detection and applications. J. Photochem. Photobiol., B, 139(5), 2-10.

Ćwintal M., Dziwulska-Hunek A., and Wilczek M., 2010. Laser stimulation effect of seeds on quality of alfalfa. Int. Agrophys., 24, 15-19.

Delibaltova V. and Ivanova R., 2006. Impact of the pre sowing irradiation of seeds by He-Ne laser on the dynamics of development of cotton varieties. J. Environ. Prot. Ecol., 7, 909-917.

Devaraj B., Usa M., and Inaba H., 1997. Biophotons: ultraweak light emission from living systems. Cur. Opin. Solid State Mater. Sci., 2, 188-193. 
Dinoev S., Antonov M., and Stoyanov T., 2006. Spectral impact of low-power laser radiation on wheat and maize parameters. Probl. Eng. Cybernet. Robotics, 54, 74-85.

Graeber K., Nakabayashi K., Miatton E., Leubner-Metzger G., and Scoppe W., 2012. Molecular mechanisms of seed dormancy. Plant Cell Environ., 35, 1769-1786.

Gujjaiah S. and Kumari Ch., 2013. Evaluation of changes in $\alpha$-amylase, $\beta$-amylase and protease during germination of cereals. Int. J Agric. Sci. Res., 3(3), 55-62.

Flórez M., Carbonell M.V., and Martinez E., 2007. Exposure of maize seeds to stationary magnetic field: effects of germination and early growth. Environ. Exp. Bot., 59, 68-75.

Gladyszewska B., 2011. Estimation of a laser biostimulation dose. Int. Agrophys., 25, 403-405.

Hardin J.M. and Stutte Ch.A., 1981. Analysis of plant hormones using high-performance liquid chromatography. J. Chromatography, 208,124-128.

Hernandez A.C., Carballo C.A., Artola A., and Mitschenko A., 2006. Laser irradiation effects on maize field performance. Seed Sci. Technol., 34, 193-197.

Hernandez A.C., Dominiquez P.A., Cruz O.A., Ivanov R., Carballo C.A., and Zepeda B.R., 2010. Laser in agriculture. Int. Agrophys., 24, 407-422.

Hernandez A.C., Dominiguez P.A., Cruz O.A., Ivanov R., Carballo C.A., Zepeda B.R., and Galingo S.L., 2009. Laser irradiation effects on field performance of maize seed genotypes. Int. Agrophys., 23, 327-332.

Jamil Y., Perveen R., Ashraf M., Ali Q., Igbal M., and Ahmad M.R., 2013. He-Ne laser-induced changes in germination, thermodynamic parameters, internal energy and enzyme activities of wheat during germination and early growth physiological attributes. Laser Phys. Lett., 10(4), doi:10.1088/1612-2011/10/4/045606.

Jun Lin W., Xuehong G., and Sheqi Z., 2007. Effect of laser pretreatment on germination and membrane lipid peroxidation of Chinese pine seeds under drought stress. Front Biol. China, 2, 314-317.

Kinugasa T., Hikosaka K., and Hirose T., 2005. Respiration and reproductive effort in Xanthium canadense. Ann. Bot., 96, 81-89.

Makarska E., Michalak M., and Wesołowska-Trojanowska M., 2004. Influence of laser irradiation on the seed quality and antioxidant contents on chosen varieties of winter wheat (in Polish). Acta Agrophysica, 111, 407-417.

Miransari M. and Smith D.L., 2014. Plant hormones and germination. Environ. Exp. Bot., 99, 110-121.

Muszyński S. and Gladyszewska B., 2008. Representation of $\mathrm{He}-\mathrm{Ne}$ laser irradiation effect on radish seeds with selected germination indices. Int. Agrophysics, 22, 151-157.

Nandi S., Das G., and Sen-Mandi S., 1995. $\beta$-amylase activity as an index for germination potential in rice. Ann. Bot., 75, 463-467.

Osman Y.A.H., El-Tobgy K.M.K., and El-Sherbini E.S.A., 2009. Effect of laser radiation treatments on growth, yield and chemical constituents of fennel and coriander plants. J. Appl. Sci. Res., 5, 244-252.
Ouf S.A. and Abdel-Hardy N.F., 1999. Influence of He-Ne laser irradiation of soybean seeds on seed mycoflora, growth, nodulation, and resistance to Fusarium solani. Folia Microbiol., 44(4), 388-396.

Perveen R., Ali Q., Ashraf M., Al-Qurainy F., Jamil Y., and Ahmad M.R., 2010. Effects of different doses of low power continuous wave He-Ne laser radiation on some seed thermodynamic and germination parameters, and potential enzymes involved in seed germination of sunflower (Helianthus annuus L.). Photochem. Photobiol., 86, 1050-1055.

Podleśny J., 2002. The effect of treating seeds with laser light on development and dynamics of dry matter accumulation by white lupine (in Polish). Monografie i Rozprawy Naukowe IUNG Puławy, 3, 1-191.

Podleśny J., Pietruszewski S., and Podleśna A., 2004. Efficiency of magnetic biostimulation of broad bean cultivated in the experimental plot conditions. Int. Agrophysics, 18, 65-71.

Podleśny J. and Podleśna A., 2004. Morphological changes and yielding of chosen legumes plants under influence of seeds treatment by laser light. Int. Agrophysics, 18, 253-260.

Podleśny J., Stochmal A., Podleśna A., and Misiak L.E., 2012. Effect of laser treatment on some biochemical and physiological processes in seeds and seedlings of white lupine and faba bean. Plant Growth Regul., 67, 227-233.

Rochalska M. and Orzeszko-Rywka A., 2008. Influence of alternating magnetic field on respiration of sugar beet seeds. Int. Agrophysics, 22, 255-259.

Rubinov A.N., 2003. Physical grounds for biological effect of laser radiation. J. Phys., 6, 2317-2330.

Rybiński W. and Garczyński S., 2004. Influence of laser ligh on leaf area and parameters of photosynthetic activity in DH lines of spring barley (Hordeum vulgare L.). Int. Agrophysics, 18, 261-267.

Somogy-Nelson M., 1952. Notes on sugar determination. J. Biol. Chem., 19, 195.

Szwejkowska B., 2006. Reaction of pea (Pisum sativum L.) cultivars to different weed control methods (in Polsh). Acta Sci. Pol., Agricultura, 5(1), 71-82.

Tillberg E., 1977. Indoleacetic acid levels in Phaseolus, Zea, and Pincus during seed germination. Plant Physiol., 60, 317-319.

Tobgy K.M.K., Osman Y.A.H., and Sherbini S., 2009. Effect of laser radiation on growth, yield and chemical constituents of anise and cumin plants. J. Appl. Sci. Res., 5, 522-528.

Vasilevski G., 2003. Perspectives of the application of biophysical methods in sustainable agriculture. Bulg. J. Plant Physiol., Special Issue, 179-186.

Voisin A.S., Gueguen J., Huyghe C., Jeuffroy M.H., Magrini M.B., Meynard J.M., Mougel C., Pellarin S., and Pelzer E., 2014. Legumes for feed, food, biomaterials and bioenergy in Europe: a review. Agron. Sustain. Dev., 34, 361-380.

Voisin A.S., Salon C., Jeudy C., and Warembourg F.R., 2003. Symbiotic $\mathrm{N}_{2}$ fixation activity in relation to $\mathrm{C}$ economy of Pisum sativum L. as a function of plant phenology. J. Exp. Bot., 54, 393, 2733-2744.

Wood A.J. and Roper J., 2000. A simple and nondestructive technique for measuring plant growth and development. American Biology Teacher, 62, 215-217. 